\title{
IMAGEM RECOLOCADA: PENSAR A IMAGEM COMO INSTRUMENTO DE PESQUISA E ANÁLISE DO PENSAMENTO COLETIVO.
}

\author{
Ana Luiza Carvalho da Rocha e Cornelia Eckert ${ }^{1}$
}

\section{Introdução}

Sem dúvida, o século XX foi o século do "trabalho" da memória. Não mais de uma transmissão oral de memórias coletivas apenas, mas a memória revisitada, divulgada, analisada, comparada pelas ciências, pela literatura, pelas artes, enfim, foram múltiplas as formas de tradução (interpretação) da memória do mundo. Um saber sobretudo captado, registrado e divulgado no âmbito das transformações urbanoindustriais, pelo industrialismo associado ao progresso da técnica como parte constituinte do agenciamento humano do tempo, na relação tecnologia/sociedade. Novas narrativas, novas competências de linguagem, mas também mudanças na discursividade e nas formas estéticas de viver o mundo captadas com clareza por Walter Benjamin ao refletir que as novas tecnologias (inauguradas com o cinematógrafo e a sofisticação dos experimentos com a técnica da fotografia no século XX) trariam modificações profundas no aparato perceptivo do homem urbano-moderno.

A técnica de registro visual, desde aí, revela ao homem moderno sua capacidade de desvendar mundos sensíveis que não eram antes percebidos: a poética nas formas interativas ordinárias e cotidianas, por exemplo, o conhecimento e a precisão dos fatos observados pela ciência; a composição dos movimentos que encerram as ações de homens e animais em seus detalhes estruturais, etc. Impossível não se perceber que as atuais invenções tecnológicas no âmbito da produção da imagem audiovisual são herdeiras legítimas do ideário da Modernidade que conforma um olhar humano sobre o mundo cuja finalidade é, precisamente, observar e dissecar a realidade para melhor descrevê-la e dominá- la ${ }^{2}$.

Paradoxalmente, no caso do filme documental que se origina a partir de experimentos com a técnica da fotografia, segundo a intenção de um olhar voltado para a análise/decomposição do átomo fotográfico em instantes temporais sucessivos, sua maturação só é atingida quando as artes do ilusionismo invadem a cena

\footnotetext{
${ }^{1}$ Coordenadoras do Núcleo de Antropologia Visual e do Banco de Imagem e Efeitos Visuais, Laboratório de Antropologia Social, PPGAS, UFRGS.

${ }^{2}$ A idéia do fusil fotográfico, disparando a intervalos regulares de Demeny e do uso de inúmeras câmeras para capturar o fenômeno em suas diferentes posições (Marey).
} 
cinematográfica, isto é, no momento em que este olhar objetiva não só a dissecação, mas a restauração do átomo fotográfico, através da simulação dos seus movimentos sucessivos projetados na sala escura, revelando tudo o que antecede a cena registrada nos termos de uma hierarquia de instantes. A arte cinematográfica propriamente dita nasce, assim, da conformação de uma linguagem que se caracteriza pela negação da sua base técnica, descontínua, fragmentada, granular.

É justamente o caráter de ilusão do movimento que a imagem cinematográfica recria em sua maturidade, que a faz coetânea ao estudo do ato de poiésis que preside os jogos da memória e o fenômeno da duração, nos termos da matriz de conceitos das ciências humanas da época ${ }^{3}$, através de uma interrogação crescente sobre o sentido do tempo restaurado, individual, social e coletivamente ${ }^{4}$, e onde não se pode pressupor a inautenticidade dos resultados com "base na artificialidade dos meios". 5

\section{O filme documental: a civilização urbana e o fascínio da técnica}

Retomamos o tema deste artigo com uma frase de Paul Ricoeur, "a história responde pelo homem" 6 , propondo revisitar o processo de produção audiovisual em Antropologia. Este percurso permite situar o documental e as tecnologias audiovisuais como parte integrante de formas de pensar as inflexões temporais características do mundo urbano contemporâneo. Produção esta que por tais qualidades, são nominados aqui de documentários "etnográficos" uma vez que propõem-se, a partir dos esquemas enunciativos da Antropologia, restaurar visualmente, através de fatos organizados numa sucessão temporal no interior de uma história considerada no cômputo de uma tradição narrativa específica, as relações entre os acontecimentos ou incidentes individuais vividos por grupos humanos que não pertencem, necessariamente, a mesma "comunidade linguística". 7

Como sugere cada vez mais a análise compreensiva do fenômeno da memória no

\footnotetext{
${ }^{3}$ Impossível aqui não reunir, a um só tempo, os estudos bergsonianos sobre o a matéria e a memória, em suas relações com o surrealismo nas artes visuais, os estudo de Braudel sobre memória e história, os estudos freudianos sobre o inconsciente, etc. e o "espírito do tempo" que rege a políticas dos impérios coloniais, em seu processo de aniquilamento e assujeitamento de povos e culturas não-ocidentais, além dos efeitos de devastação e destruição oriundos da I Guerra Mundial sobre as bases filosóficas da própria civilização européia.

4 Ver a respeito comentários de Lev Manovich, "From the externalization fo the Psyche to the implantation of technology", sobre as concepções fílmicas do cinema russo, na pessoa de Eisenstein, e Rosenthal, El documental, no que tange as concepções do documental em Dziga Vertov e R. Flaherty, e Arlindo Machado, Pré-cinema e pós-cinema, sobre as produções de Griftih e S.Eisenstein.

${ }^{5}$ A Machado, Pré-cinemas e pós-cinemas.

${ }^{6}$ Cf. P. Ricoeur, Tempo e Narrativa. Campinas, Papirus, 1994, Vol. I.

${ }^{7}$ Cf. Michel De Ceretau, "A invenção do cotidiano".
} 
mundo contemporâneo, o tempo torna-se humano na medida em que está articulado na forma narrativa e que as ações humanas apresentam-se como "totalidades altamente organizadas" numa sucessão ${ }^{8}$.

Neste sentido, a produção de documentos "etnográficos", com base na linguagem das tecnologias audiovisuais, sugere a necessidade de lembrarmos, aqui, o espaço estratégico que ocupa tal tradição narrativa na constituição da história a ser narrada pelo antropólogo, uma vez que ela é acompanhada de operações simbólicas específicas de compreensão e organização das ações humanas. Ou seja, explorar os seus recursos ilusionistas, simulando o tempo num continuum de instantes logicamente hierarquizados, quando, no entanto, sua feição é granular e fragmentária.

Lembrar o ilusionismo e os efeitos de simulação técnica da unidade temporal que presidem a arte de narrar, tanto no cinema ficcional quanto no cinema documental, e suas interfaces, para o caso da Antropologia, é não esquecer o comprometimento da produção de filmes etnográfico com o campo da narrativa. Em especial, no que se refere aqueles dedicados a descrição dos fenômenos da memória. Tal "lembrança" traz algumas implicações particulares na medida em que muitos dos filmes "etnográficos" acabaram, mesmo sem o desejar, por "documentar", através de seu relato descritivo, os traços da aventura temporal humana que constitui o trabalho antropológico, explorando, ainda que implicitamente, os procedimentos de interpretação do mundo que comportam tais tecnologias e de sua feição de máquinas criadas no sentido da exteriorização de processos mentais ${ }^{9}$.

O caso de dois filmes documentais clássicos, diferentes em seus estilos, e que tanto inspiraram os antropólogos-cinegrafistas, podem ser aqui exemplares: Nanook, de Robert Flaherty - cuja linguagem visual explora as seqüências da ação baseadas em idéias e representação de episódios em vários ângulos, com a inclusão de planos e contra-planos, de movimentos panorâmicos e angulações para permitir revelações de pontos de vista - e o "O homem e a câmera", de Dziga Vertov - onde o documento, de mise-en scène assume o papel de registro da "prosa da vida", através do uso da câmera oculta que, tal qual o olho humano, destituído de corpo, sem restrições, em posições apropriadas, move-se na captura de impressões.

Pensando a posteriori a respeito dos estudos em cronofotografia que incorpora o

\footnotetext{
${ }^{8}$ Cf. artigo de L. Minck, "The autonomy of historical understanding", Review of Metaphysics 20 (1968), pp.667-698, e citado por P. Ricoeur, op. cit., pp.223-228.

${ }^{9}$ Ver a respeito Lev Manovich, "From externalization of the psyche implantation of tecnology".
} 
fenômeno temporal nos experimentos fotográficos, podemos observar que eles são os antecessores, de inúmeras maneiras, não só do cinema, mas do filme documental. Entre ambos, entretanto, estabelece-se uma diferença expressiva no tratamento da imagem, em particular no que se refere ao gênero documental. Enquanto, na cronofotografia, tratava-se de decompor, no detalhe, a imagem capturada, reforçando-a como dado analógico do mundo social que o olho humano não poderia ver, no caso do filme documental, diferentemente do cinema de ficção, o compromisso do documentarista com a captura do microcosmo das engrenagens que presidiam a vida social, esquecia-se que ao momento de sua recriação virtual na tela de uma sala escura, tratava-se de uma simulação.

Hoje, entretanto, sabe-se perfeitamente que a fotografia e o cinema participam de uma "cultura visual" de forma diferencial cada qual a seu modo. A fotografia, como a pintura renascentista, explora a tela clássica, face a qual o espectador adota uma visão frontal; como numa janela para o mundo, o espectador confronta-se com escalas de representação diferenciais. O cinema, inaugurando as atuais telas de computadores, explora a imersão do espectador, face a uma tela dinâmica, onde os limites entre o espaço da representação e o espaço físico se esvanecem.

Tais observações têm, certamente, consequiências na forma como se pode perceber, hoje, o tratamento conceitual a ser dado aos documentários etnográficos, em particular, aqueles que se atém ao fenômeno da memória tendo por intenção estética expressar os mistérios da duração. A idéia do documental, seja na fotografia, seja no cinema, concebido como prova e testemunho do vivido humano, tal qual aquela empregada, desde suas origens, para o registro de fatos e acontecimentos nas expedições/explorações, na medicina, nas questões militares, na ciência e na educação, revelam-se assim, diferencialmente, como fenômenos que fazem parte de uma "cultura visual" singular.

O registro documental dos fatos sociais, em suas dimensões de captura do fenômeno do desencaixe espaço/tempo "moderno" e de acontecimento, na contemporaneidade, está intimamente associado, portanto, a conformação da civilização urbano-industrial. Isto é, um território de vida social singular, ávido de inovações tecnológicas, seduzido pela figura do estrangeiro e adepto a idéia de aventura ${ }^{10}$.

Da mesma forma que a fotografia relaciona-se a ambiência psicosocial

\footnotetext{
${ }^{10}$ Cf. Simmel,
} 
moderna, ${ }^{11}$ ao permitir que as formas do mundo pudessem ser perpetuadas, copiadas, fabricadas, multiplicadas e distribuídas; o cinema é tributário da manipulação das estruturas espaço-temporais criadas no bojo do mundo contemporâneo: a eletricidade como fenômeno que orienta o controle dos ritmos naturais do tempo nos grandes centros industriais, a formação de grandes impérios coloniais e o encurtamento das distâncias que separavam o homem ocidental de povos e civilizações, antes longínquos; o crescimento de consumo cultural do exótico e do bizarro e o desenvolvimento da indústria do turismo e sua sede voraz de novas paisagens humanas e naturais, etc.

Um mundo que floresce à sombra de uma indústria de entretenimento cada vez mais sofisticada, cuja tendência colonialista disponibilizava às elites o consumo cultural de povos e costumes exóticos, situados em regiões insólitas, e que apresentados como novidades, apeteciam o seu gosto pela erudição e pela informação.

Inicialmente configurado nos termos de "notícias ilustradas", o documental (fotográfico ou cinematográfico) vai explorar o traço espetacular de fenômenos ordinários da vida social nas grandes metrópoles ${ }^{12}$, e mesmo fora dela. Tratava-se, sem dúvida, de atender a presença de um público interessado em assuntos breves, no bojo dos quais estavam contido os temas da exploração/extinção de culturas e povos, do diaa-dia das grandes cidades, das transformações das zonas rurais e de aldeias face aos avanços de uma sociedade industrial e dos grandes impérios coloniais da Europa ocidental, em termos mundiais.

Se, por um lado, tais "documentos" atendiam o consumo do exotismo, nos quadros de uma celebração do próprio homem ocidental, europeu, branco e civilizado, por outro, traduziam uma demanda arquivística cada vez mais presente à formação da cultura objetiva no Ocidente moderno, progressivamente voltada ao fenômeno do registro das transformações de determinados aspectos da cena cultural local e mundial. Somente mais tarde, com o surgimento dos famosos "noticiários", esta via de produção documental acabaria por esgotar-se, dando nascimento a transformações no próprio gênero do filme documental.

Não é por acaso que o fascínio pela imagem no seio de uma sociedade dividida entre razão e emoção provocará, no gênero documental, uma preocupação exacerbada

\footnotetext{
${ }^{11}$ Cf. Benjamin,

12 Vejamos, por exemplo, o caso dos irmãos Lumière, profeta do filme documental, sua equipe de cinegrafistas e operadores de câmera, a deslocarem-se pelo mundo afora na captura de "atualidades", em razão da tecnologia por eles adotada, de fácil manejo e transporte para regiões as mais diversas e as mais inóspitas.
} 
com o tema da autenticidade, na defesa de seu status de "prova fílmica", contrário ao uso cada vez mais crescente dos jogos de simulação no plano de sua construção narrativa, e que deu origem ao filme de ficção.

Nossas interrogações aqui a respeito do filme etnográfico convergem, portanto, para a necessidade de uma reflexão mais acurada a respeito do tema da produção/criação de imagens e o tema documental, tendo como foco de atenção seus vínculos com as transformações sofridas pelas noções de testemunho/autenticidade/verdade no cômputo do mundo urbano-contemporâneo.

\section{A produção de documentários etnográficos: condições intratextuais e intratemporais}

A produção de filmes etnográficos, sob o enfoque documental, nos mergulha, assim, em certas tradições do pensamento típicas da sociedade ocidental moderna, e que implicam em saber ver, escutar, escrever, representar, narrar, enfim, conhecer e conhecer-se a tal ponto que uma investigação a partir da imagem nos remete, hoje, a construção de nossas próprias imagens internas, isto é, as formas simbólicas através das qual o próprio conhecimento antropológico se expressa.

Neste ponto, a produção de filmes etnográficos trouxe consigo as influências dos métodos e técnicas da matriz disciplinar da Antropologia na configuração do próprio gênero documental e na forma como este concebe o ato de narrar o mundo social. Cada vez mais o gênero documental adotado pelo etnógrafo revela-se um ato compreensivo que lhe exige um olhar treinado sobre a vida social. Parodiando as palavras de Paul Ricouer, o processo intelectual gerador de narrativas etnográficas, com base nos recursos audiovisuais, pode ser descrito a partir da metáfora da "flecha do tempo" que, deslocando-se, desenha um espaço, modela uma forma.

Em particular, o desafio da construção de um documentário etnográfico reside no fato de que, na sua elaboração, a linguagem ordinária do próprio pesquisador é jogada para além de si mesma uma vez que, ao contar algo, o antropólogo precisa formar juízos reflexivos a partir dos quais o mundo social é narrado.

No caso de produções voltadas ao tema da memória, estas são realizações complexas que exigem prudência dos cineastas na medida em que sua consecução implica considerar-se o tema da tradução cultural para uma experiência temporal que 
possui múltiplas dimensões ${ }^{13}$. Tal processo funda-se na ordenação "lógica" de, no mínimo, três modos de representar ou imitar uma situação passada e vivida: o tempo prefigurado, da experiência temporal prática dos grupos humanos, inclusive do próprio etnógrafo, referido ao roteiro de gravação em campo, que precede a tessitura da intriga a ser narrada e se traduz no problema da relação entre tempo "etnográfico" e a sua modelagem enquanto narrativa; o tempo configurado, da experiência temporal pensada segundo a trama a ser apresenta, refletida num roteiro de edição e, finalmente, a mediação do tempo reconfigurado, referente à experiência do espectador com a obra produzida e a sua projeção na tela.

O que apresentamos aqui, a respeito da complexidade que percorre a consolidação do tempo da narração, no caso do filme etnográfico, já foi antes abordado, direta ou indiretamente, por inúmeros estudos antropológicos. Exemplificamos com o texto de David Mac Douggal intitulado Films de Mémoire ${ }^{14}$ onde o autor assinala que o filme ou documentário só pode ser uma representação de segunda ordem, ou melhor, uma interpretação da interpretação da memória dos sujeitos considerados na história narrada pelo filme.

Assim, David MacDougall sugere que, no campo dos fenômenos da memória, encontramos o equivalente mais próximo de uma multidimensionalidade narrativa que está presente nos sistemas variados e cruzados do filme ${ }^{15}$. E acrescenta ao seu pensamento, uma indagação: considerando-se a complexidade do fenômeno da memória e a atmosfera de irrealidade e de sonho que ela envolve, podemos nos perguntar se, ao representar a memória em filme, nós produzimos alguma coisa de significativamente diferente de outras formas de representações visuais e textuais? Conforme suas próprias palavras: 'Nós criamos os signos para as coisas vistas somente pelo olho do espírito. Trata-se, entretanto de signos como os outros"? ${ }^{16}$

O que nos interessa, em particular, no artigo de MacDougall, não é apenas o fato do autor considerar criticamente os filmes que procuraram traduzir a memória minimizando a imaginação, mas que ele reflete sobre a particularidade da competência narrativa da imagem-movimento para desenvolver uma narrativa antropológica que

\footnotetext{
${ }^{13} \mathrm{P}$. Ricouer

${ }^{14}$ MACDOUGALL, David. "Films de Mémoire". In: PIAULT, Colette (Coordination). Journal des Anthropologues, Anthropologie Visuelle, número Special 47-48, Printemps 1992.

15 "La mémoire est souvent apparemment incohérente, étrange mélange de sensoriel et de verbal. Elle nous offre le passé en éclairs et en fragments, et en ce qui paraît un fatras confus d'un média mental. Nous semblons entrevoir des images, entendre des sons, utiliser des mots non prononcés, et expérimenter à nouveau des sensations physiques, comme la tension et le mouvement.”. MACDOUGALL. 1992: 68.

${ }^{16}$ MACDOUGALL. 1992: 68.
} 
elucide as transformações nas formas de viver e de pensar de pessoas e grupos, assim como a competência etnográfica no tratamento descritivo das dinâmicas complexas que regem o fenômeno da memória. O que implicaria se repensar a tendência nominalista das produções antropológicas (fílmicas, fotográficas, textuais) que abordam o tratamento conceitual da memória na medida em que narram as interpretações de eventos e acontecimentos passados na crença de reproduzi-los como testemunho autêntico e verídico de uma realidade factual.

Concordar com as observações deste autor, entretanto, não significa aqui adotar uma posição epistemológica que aposta no caráter de ilusão para o caso do tratamento conceitual da memória, através de documentos etnográficos, atribuindo-lhes um caráter de ilusão, em geral psicológica. Reconhecer que os jogos da memória estão atrelados às operações do pensamento humano não nos leva a reduzi-los a um mero resíduo "material" da consciência, por outro lado, apregoar o lugar da imaginação criadora como elemento formal do pensamento não nos conduz a concluir que tais jogos sejam apenas produtos de estados psicológicos, desvinculado de suas operações com o real.

Sob o ponto de vista geral da compreensão narrativa que encerra a produção de uma obra etnográfica, vale assinalar, aqui, o "potencial hermenêutico" que ela contempla (sem ignorarmos aqui a estrutura semântica da ação narrada, seus recursos de simbolização ou do caráter temporal "construído"), e que envolve, necessariamente, a explicitação do conjunto de operações intelectuais através das quais o antropólogo faz a experiência temporal elevar-se do "fundo opaco do viver, do agir e do sofrer" 17 humano, traduzindo-a para um leitor que a recebe e, assim, muda seu ponto de vista sobre o sentido de suas próprias lembranças.

Neste ponto, na linha da argumentação de MacDougall, pode-se insistir que o processo de conceitualização que subsidia a produção documental de um filme etnográfico funda-se na arte de narrar, ou seja, na atividade do tecer da intriga decorrente de operações cognitivas específicas através das quais o antropólogo extrai de uma simples sucessão de acontecimentos uma configuração de sentido, construída na ordem da linguagem cinematográfica, através de suas formas simbólicas expressivas.

As bases filosóficas mais sólidas do que afirmamos acima esta na crítica a "vaga impessoalista" com as quais se procura refletir sobre as obras humanas, inspirando-nos nas tramas de uma filosofia da cultura concebida por Nietzsche e Cassirer, em suas

\footnotetext{
${ }^{17}$ P.Ricoeur
} 
críticas radicais à noção de sujeito tal qual foi consolidada pelo racionalismo de Descartes.

Verdade/testemunho/autenticidade/documento são os pilares do valor desta "vaga impessoalista" que sustenta a proposição puramente lógica no tratamento documental do fenômeno da memória. Neste caso, a crença da imagem-técnica como evidência objetiva das ações humanas no mundo se afirma na linha da argumentação que propõe ser a verdade etnográfica algo contrário ao olhar subjetivo e ao ato passional. Como buscamos alertar no início deste artigo, a objetividade atribuída ao caráter documental da fotografia ou do filme atestam sua conformidade aos interesses de uma forma histórica determinada de vida.

Neste sentido, o par autenticidade/verdade é considerado fora de sua significação ético-moral, eliminado-se as indagações a respeito dos arranjos entre as estruturas cognitivas e as forças pulsionais humanas e o meio cósmico e social e afastando-o da aventura que encerra a configuração do conhecimento humano, para além do cogito e da razão.

\section{O documental na construção de narrativas etnográficas audiovisuais}

Portanto, tratar a noção de memória, não na mera descrição dos signos exteriores evocados pela lembrança, segundo o estatuto estéril de conteúdos subjetivos, quase sensoriais, mas como interpretações indispensáveis à compreensão de narrativas inteligentes do vivido humano, é, aliás, no nosso ver, a riqueza de se construir uma etnografia com base em registros audiovisuais, considerando-se aqui que toda a lógica do próprio pensamento que pensa a distensão temporal escapa a imagem.

A produção de um vídeo documentário cuja preocupação seja os jogos da memória, e seu tratamento através da imagem-movimento, na linha da argumentação adotada, exige que se trabalhe, primeiramente, a imagem captada e registrada no sentido desta ser uma representação operatória do real. Posteriormente, os temas da autenticidade/veracidade das imagens que aludem aos testemunhos, aos fatos, aos acontecimentos ou as situações retratadas pelo etnógrafo na produção de um documentário, serão jogadas no plano da construção das representações simbólicas, sendo o desafio da montagem a possibilidade de re-construção de uma intriga onde o antropólogo estabelece o pertencimento da ação narrada a um conjunto de traços estruturais de uma dada ordem simbólica, portanto, cultural.

A partir de um roteiro de edição, o antropólogo, na figura do documentarista, 
deverá incubir-se, assim, da árdua tarefa de fazer concordar, em proporções variáveis, pelas duas dimensões temporais significativas para que a obra produzida possa acender ao estatuto de obra etnográfica: o tempo cronológico (a dimensão episódica da narrativa tal qual vivida pelo antropólogo em seus registros de campo) e a não-cronológica (a dimensão propriamente configurante) que o confronta ao problema da tradução cultural, e graças a qual o documentarista consegue transformar os acontecimentos isolados, obtidos em campo, numa totalidade temporal.

Neste ponto, a ação experimentada pelos sujeitos da memória (memória-sujeito), incluindo-se aí a história da própria pesquisa etnográfica, acabam por integrar a trama narrada. Os recursos da linguagem cinematográfica, no caso da dramatização da narrativa adotada para tal gênero de documentário, podem significar recursos estilísticos suficientemente sólidos para mimetizar a experiência etnográfica do antropólogo na descoberta da forma singular dos pesquisados ordenarem suas temporalidades e vivenciarem relações múltiplas nos espaços de suas tramas de ação.

Pode-se aludir aqui ao fato de todo o documentário etnográfico, no fundo, singularizar-se por sua tendência a "mimetizar" o próprio processo através do qual o antropólogo atinge a compreensão aproximativa com a realidade investigada, na tentativa de provocar no "leitor/espectador" o estranhamento dos seus próprios códigos culturais e a descentração de seu lugar no mundo, configurando no corpo do documentário, o próprio processo de descoberta do outro.

Nesta medida, o documentário etnográfico, de forma geral, tenderia a desestabilizar o saber de referência de seus leitores/espectadores e as concepções cotidianas a partir das quais eles interpretam suas ações no mundo, levando-os a reconfigurarem a própria experiência do antropólogo e, partindo de sua própria experiência de vida, a situarem a sua própria experiência temporal nos quadros das diferenças culturais.

Assim, ao elaborar uma significação articulada das ações humanas ao longo do tempo, pela via da linguagem cinematográfica, exige-se do antropólogo-documentarista uma competência suplementar, ou seja, a sua competência em operar com as mediações simbólicas da ação humana num todo ordenado de elementos assim como o território de suas manifestações considerando-se alguns pontos importantes de um processo de conceitualização do fenômeno da memória. Ou seja, os caracteres temporais de onde procedem mais diretamente as ações investigadas e retratadas no documentário: a capacidade dramática de tais ações e suas possibilidades de serem narradas por recursos 
audiovisuais e, finalmente, a construção de invariantes operatórias (esquemas) das ações e intenções dos atores/personagens da história a ser narrada, a partir da suas diferenciações, e segundo suas propriedades e relações internas distintas.

A construção de uma obra etnográfica através dos recursos audiovisuais desafia, como no caso das etnografias mais convencionais, com base na tecnologia da escrita, o autor e o leitor a atingirem, assim, o plano da "intratemporalidade" na qual se tece o caráter documental da experiência/existência humana narrada. Atingir o grau de compreensão da "intratemporalidade" que tece o sentido das ações/vidas humanas significa para ambos, atingir operações cognitivas complexas a partir das quais a representação cronológica do tempo das vidas/escolhas humanas através de sucessão de "agoras abstratos" se rompe.

\section{BIBLIOGRAFIA}

BACHELARD, G. La dialectique de la durée. Paris, Quadrige/PUF, 1989. (1ed 1950). BENJAMIN, Walter. Obras Escolhidas. I, II, III. São Paulo, Brasiliense, 1985. BERGSON, Henri. Matéria e Memória. S.P. Martins Fontes, 1990.

BOSI, Ecléa. Memória e sociedade. Lembranças de velhos. São Paulo, Queiroz Ed.ltda. e EDUSP, 1987.

CASSIRER, Ernst. Ensaio sobre o homem, introdução a uma filosofia da cultura humana. São Paulo, Martins Fontes, 1994. P. 87 a 90.

Deleuze, G. A Imagem-Movimento, Cinema II, SP, Brasiliense, 1990, p.62. DENIS, Michel. Les Images Mentales, Paris, Puf, 1979.

DURAND, Gilbert. Les structures anthropologiques de l'imaginaire. Paris, Dunod, 1980.

ELIADE, M. Traité d'histoire des religions, Paris, Payot, 1979, Granet, La pensée chinoise, Paros, Albin-Michel, 1968

GRIAULE, M. Dieu d'eau, Paris, Fayard, 1966

MAC DOUGALL, David. "Films de Mémoire". In: PIAULT, Colette (Coordination). Journal des Anthropologues, Anthropologie Visuelle, número Special 47-48, Printemps 1992 p. 75

MACHADO, A. Pré-cinemas e pós-cinemas

MINCK, L. "The autonomy of historical understanding”, Review of Metaphysics 20 (1968), pp.667-698, e citado por P. Ricoeur, op. cit., pp.223-228 
PIAGET E INHELDER, La répresentation de l'espace chez l'enfant,

PIAGET, Jean. Sabedoria e Ilusões da Filosofia, São Paulo, Editora Abril, 1978.

RICOEUR, P. Tempo e Narrativa. Campinas, Papirus, 1994, Vol. I. 